\title{
Distribution of plasminogen activator inhibitor (PAI-1) in tissues
}

\author{
A J Simpson, N A Booth, N R Moore, B Bennett
}

\begin{abstract}
Extracts of human tissue were analysed for plasminogen activator inhibitor (PAI-1) antigen and activity. PAI-1 was localised in tissues by an immunochemical method, using monoclonal antibodies. PAI-1 occurred throughout the body; its concentration and activity differed considerably from organ to organ. Extracts of liver and spleen had the greatest abundance of PAI-1, but the activity of the inhibitor was much higher in liver than in spleen: the liver may be a source of plasma PAI-1. Immunochemical staining for PAI-1 was observed in endothelium, platelets and their precursor cells, the megakaryocytes, and locations central to the process of haemostasis. PAI-1 also occurred in neutrophil polymorphs and macrophages, cells important in inflammatory and immune processes, but not in lymphocytes. Other cell types, in particular, vascular smooth muscle cells and mesangial cells, also stained positively for PAI-1 and such cells seem to represent an important reservoir of PAI-1.
\end{abstract}

The proteolytic conversion of plasminogen to plasmin effected by the plasminogen activators t-PA and u-PA is central to the process of fibrinolysis. These activators can be efficiently inhibited by plasminogen activator inhibitor PAI $-1,{ }^{1}$ which is the principal regulator of t-PA and u-PA activity and consequently of plasmin generation.

In human blood PAI-1 occurs in plasma ${ }^{23}$ and in platelets. ${ }^{45}$ PAI- 1 in plasma is of low concentration but has relatively high specific activity; platelet PAI-1 is of low specific activity but accounts for around $93 \%$ of total circulating PAI-1 in normal human blood. ${ }^{6}$ The discovery of PAI-1 in human blood has prompted the suggestion that changed blood concentrations of the inhibitor may contribute to the pathogenesis of thrombotic or haemorrhagic disorders. Indeed, increased plasma PAI activity has been shown in a wide variety of conditions, including deep venous thrombosis and myocardial infarction. ${ }^{7}$ This picture is confused, however, by the fact that plasma PAI-1 is increased in several disorders, and by its acknowledged role as an acute phase reactant. ${ }^{8-10}$

In addition to plasma and platelets, PAI-1 has also been identified in various cells in culture. In this way endothelial cells, smooth muscle cells, hepatocytes, fibroblasts and certain tumour cell lines have been shown to produce PAI-1. The distribution of PAI-1 in different human organs and tissues has not yet, however, been systematically studied. Clearly it is important to define cells containing PAI-1 to improve our understanding of the importance of this inhibitor in haemostasis and other processes.

\section{Methods}

Tissue samples from liver, spleen, kidney, lung, myocardium and brain were obtained at necropsy from four subjects. The causes of death were, respectively, perforated viscus, pulmonary embolus, myocardial infarction and peritonitis. Samples were always obtained within 24 hours of death.

Tissue fragments of about $2 \mathrm{~g}$ were extensively washed with $0.9 \% \mathrm{NaCl}$ in $10 \mathrm{mM}$ phosphate buffer, $\mathrm{pH} 7 \cdot 2$, to remove residual blood. Thereafter, $1 \mathrm{~g}$ pieces were blotted dry and homogenised in $0.1 \mathrm{M}$ TRIS/ $\mathrm{HCl}$ buffer, $\mathrm{pH} 7 \cdot 4,0 \cdot 1 \%$ Tween 80 , before being centrifuged at $1800 \times g$ for 30 minutes at $4^{\circ} \mathrm{C}$. Samples were stored at $-70^{\circ} \mathrm{C}$ until assayed. Each tissue extract was assayed for PAI-1 antigen on at least four occasions.

PAI-1 antigen was assayed by an enzymelinked immunosorbent assay (ELISA). The ELISA, modified slightly as described previously, ${ }^{6}$ recognises PAI-1 in active, latent, and complexed forms. ${ }^{11}$ PAI-1 activity was determined by the method of Chmielewska and Wiman $^{12}$ with minor modifications, as previously described. ${ }^{6}$ Contamination of extracts with blood was assessed by rocket immunoelectrophoresis ${ }^{13}$ for $\alpha_{2}$-macroglobulin and $\alpha_{1}$ antitrypsin.

The alkaline phosphatase-anti alkaline phosphatase (APAAP) technique ${ }^{14}$ was used for immunohistochemistry. Tissue samples were obtained from four separate necropsies between six and 18 hours after death from, respectively, myocardial infarction $(n=2)$, pulmonary embolism $(n=1)$, and an unknown cause $(n=1)$. Umbilical cord was also obtained from normal term deliveries within two hours of birth. Samples were snap-frozen in thawing dichlorodifluoromethane and $6 \mu \mathrm{m}$ sections were cut and mounted directly on glass slides. Marrow aspirates (from two patients in remission from acute nonlymphoblastic leukaemia undergoing marrow review), obtained from routine needle aspiration of the iliac crest, peripheral blood samples (from four normal 
subjects), and mesangial cell cystospin samples (supplied by Dr D A Power of this department) were spread on glass slides. Test and control slides were prepared for all samples. At least four sections or spreads from each tissue sample were examined and each tissue was analysed on at least two separate occasions.

Slides were fixed by immersion in a $1: 1$ mixture of acetone and methanol for $10 \mathrm{~min}$ utes at $4^{\circ} \mathrm{C}$, then washed in TRIS-buffered

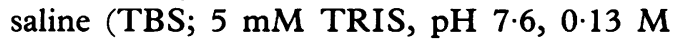
$\mathrm{NaCl}$ ) before the primary murine monoclonal IgG $_{1}$ antibodies (ESPI 1, 2, or 4) to PAI- ${ }^{15}$ were applied for one hour at room temperature; mouse IgG $_{1}$ isotype control immunoglobulins were also used. Slides were washed three times in TBS and treated with polyclonal rabbit antimouse immunoglobulins (Dakopatts, High Wycombe, Buckinghamshire), applied for 30 minutes at room temperature. Further washes in TBS were followed by the addition of APAAP complex (Dakopatts, UK) for $30 \mathrm{~min}$ utes at room temperature; APAAP consists of a conjugate of calf alkaline phosphatase bound by murine antibodies raised against the enzyme. Washes in TBS were followed by the addition of substrate solution for 15 minutes at room temperature. This solution consisted of veronal acetate buffer ( $29 \mathrm{mM}$ barbitone, 29 $\mathrm{mM}$ acetate) containing $0.05 \%(\mathrm{w} / \mathrm{v})$ naphthol AS-MX phosphate, $0.025 \%(\mathrm{w} / \mathrm{v})$ levamisole, and $0.05 \%(\mathrm{w} / \mathrm{v})$ Fast Red TR (all Sigma Chemicals, UK). After washing in water cells were lightly counterstained in haematoxylin, washed further, and examined by light microscopy, the red reaction product indicating the presence of immunoreactive PAI-1.

\section{Results}

The mean PAI-1 antigen content of a number of tissues is indicated in the table. The contents of platelets and of platelet-free plasma ${ }^{6}$ are also included for comparison. The possibility that some of the PAI-1 antigen in the extracts was derived from blood was checked by analysis of all extracts for $\alpha_{1}$-antitrypsin and $\alpha_{2}$-macroglobulin by rocket immunoelectrophoresis. These antigens were present at a range of 0 to $2 \%$ of the normal plasma concentration, indicating that blood contamination of extracts was negligible.

PAI activity was not always measurable due to the presence of plasminogen activator activity in the tissue extracts. The two tissues with the highest concentrations of PAI-1 antigen, however, differed considerably in their PAI activity. Liver PAI activity was $73 \mathrm{U} / \mathrm{g}$ of tissue, while spleen had only $2 \mathrm{U} / \mathrm{g}$. These differences could not be explained simply by plasminogen activator activity, as shown by control experiments. The large difference in activity of the PAI- 1 from the two sources was confirmed by analysis of their ability to form a complex with t-PA (data not shown).

The APAAP technique was used to examine the location of PAI-1 antigen within tissues (figure). Individual tissues from different necropsies showed consistent staining patterns. Positive staining for PAI-1 antigen was
Mean PAI-1 antigen content of several different tissues

\begin{tabular}{lcr}
\hline & \multicolumn{2}{l}{ PAI-1 antigen } \\
\cline { 2 - 3 } Tissue (ng/g wet weight) & Median & Range \\
\hline Spleen & $534 \cdot 4$ & $338 \cdot 6-893 \cdot 8$ \\
Liver & $804 \cdot 3$ & $481 \cdot 8-979 \cdot 6$ \\
Kidney & $279 \cdot 4$ & $190 \cdot 0-411 \cdot 2$ \\
Lung & $108 \cdot 1$ & $78 \cdot 0-444 \cdot 6$ \\
Myocardium & $30 \cdot 1$ & $18 \cdot 0-72 \cdot 0$ \\
Brain & $9 \cdot 8$ & $6 \cdot 4-20 \cdot 8$ \\
Plasma (ng/ml) & $20 \cdot 4$ & $8 \cdot 2-32 \cdot 5$ \\
Platelets $\left(\mathrm{ng} / 10^{4}\right)$ & 620 & $470-1160$ \\
\hline
\end{tabular}

observed in platelets, megakaryocytes, and neutrophils. No PAI-1 was detected in T or B lymphocytes on examination of reactive and non-reactive lymph nodes (not shown). Venous endothelial cells and the muscularis layer of vein walls stained positively for PAI-1. Umbilical artery endothelium and smooth muscle also contained PAI-1. Smooth muscle in several other locations-for example, in the bowel wall-also stained positively for PAI-1 (data not shown).

In the liver generalised positive staining for PAI-1 antigen was detected in hepatic parenchyma and in Kupffer cells. In the kidney positive staining was confined to a proportion of the cells present in glomeruli only (figure). It seemed likely that this represented specific staining of the mesangial cell population, as cultured mesangial cells were found to be a source of PAI-1 antigen. Renal tubular epithelium did not show positive staining.

In several tissues positive staining was noted in cells of macrophage lineage. Thus alveolar macrophages (figure), splenic macrophages, microglial cells, and as indicated above, Kupffer cells, were identified as containing PAI-1.

Myocardial cells showed virtually no positive staining. Neural tissue from the brain and spinal cord showed uniformly negative staining, except for the neuroglial elements. These findings are consistent with the low concentrations of PAI-1 in extracts of heart and brain (table).

\section{Discussion}

Considerable interest has centred on the possible role of PAI-1 in plasma and platelets in the control of intravascular events. Less is known of its contribution to extravascular processes; in particular, its distribution in human tissues has not been defined.

Our studies on extracted human tissues indicate that all organs examined contained PAI-1 antigen, but that the concentrations in different tissues varied widely. Liver and spleen contained the highest quantities of antigen, while brain and myocardium contained only tiny amounts. Not only did antigen content vary but the functional activity of the PAI-1 varied independently of antigen. Thus the PAI-1 present in liver was of higher specific activity than that in spleen.

Tissue samples for analysis were obtained at necropsy from patients with a variety of dis- 


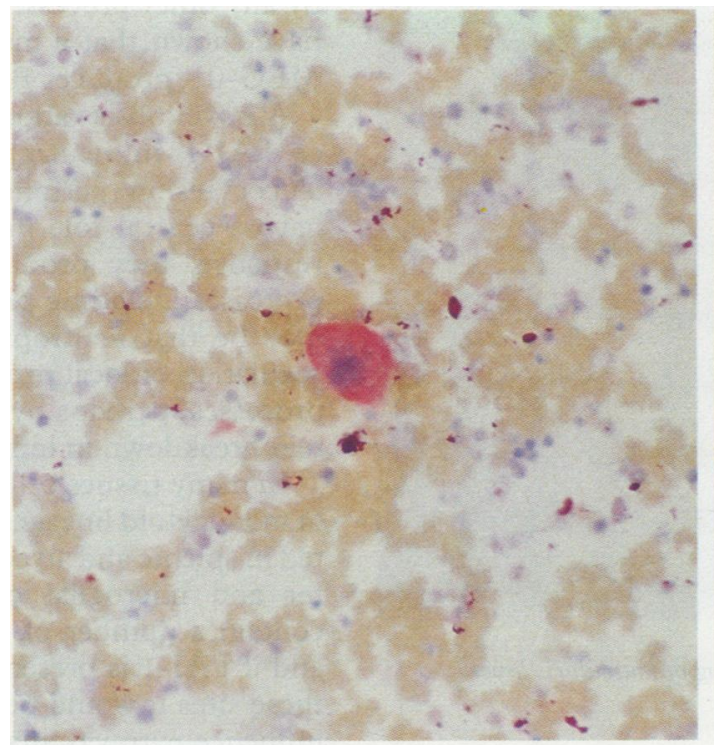

(A)

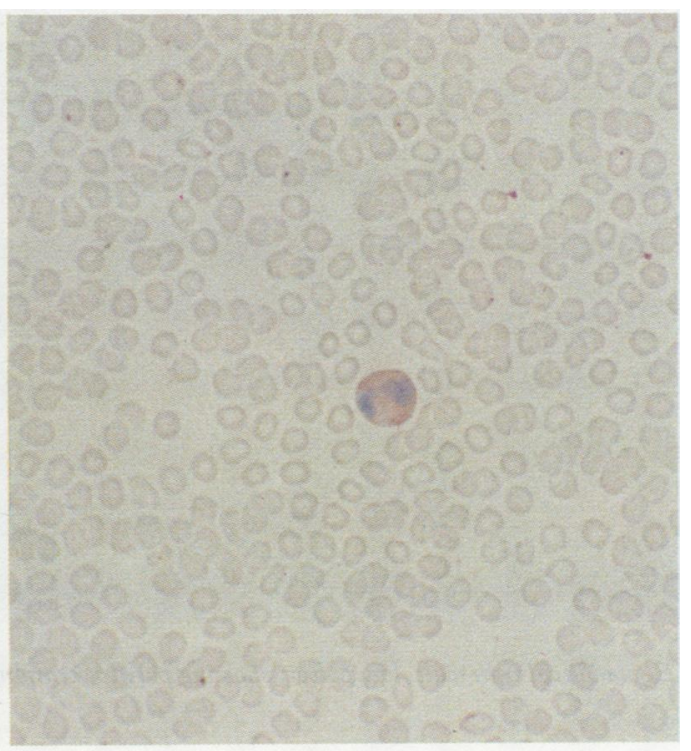

(B)

Staining of selected tissues with monoclonal antibodies to PAI-1 by the APAAP technique. (A) marrow with positivity in megakaryocyte; $(B)$ blood film with positivity in neutrophil polymorph.

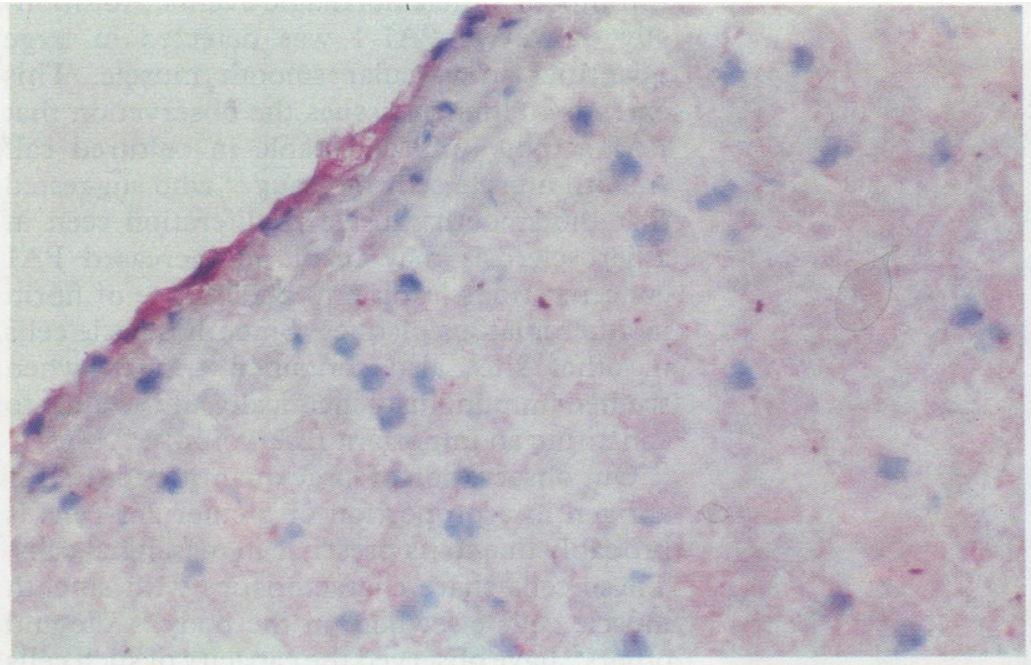

(D)

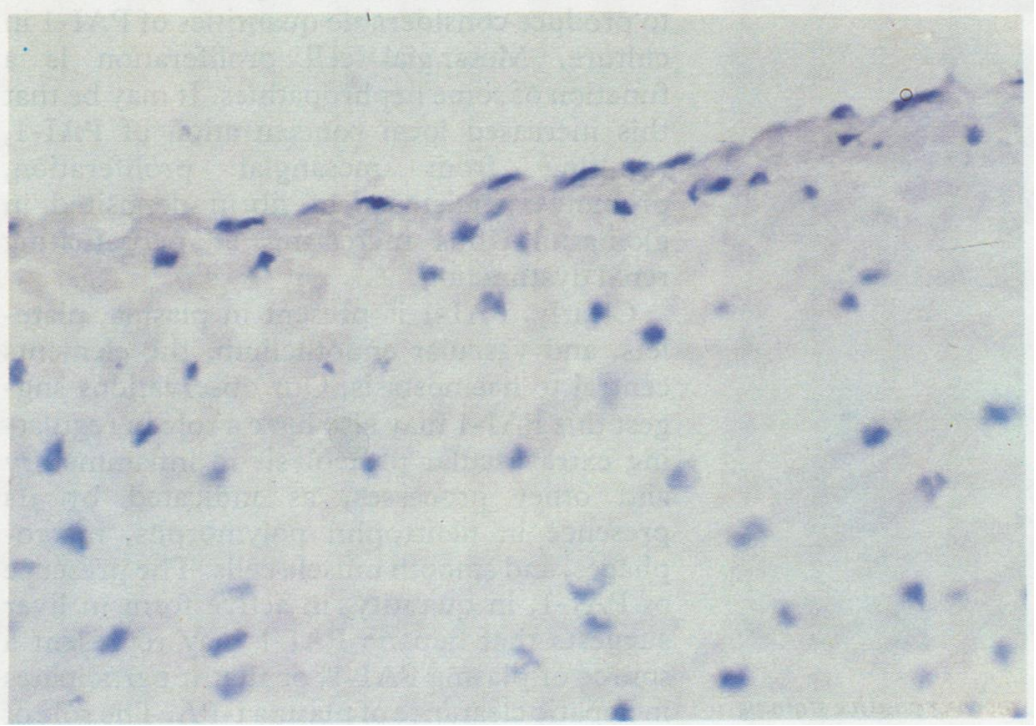

(C) umbilical vein wall showing endothelial layer positivity; (D) negative control for $(C)$. orders. The disease processes themselves or post mortem autolysis might have influenced some results. Consistent observations were made in the tissues studied, despite the different causes of death. Post mortem autolysis is not likely to have affected the distribution of PAI-1 antigen and the observed staining pattern is therefore likely to be representative of that during life. Post mortem proteolysis might have influenced PAI activity more than antigen. There was a striking difference in PAI activity between liver and spleen, the two organs containing largest quantities of antigen; hepatic PAI-1 was much more active than splenic PAI-1. It seems unlikely that post mortem change could account for this difference in activity.

Several interpretations of these findings present themselves. The origin of plasma PAI-1 remains uncertain. Vascular endothelial cells ${ }^{16}{ }^{17}$ and hepatic cells ${ }^{18}$ are potential sources of the plasma PAI-1. It may be that the active PAI-1 shown in the liver is released into the plasma, where the protein also has relatively high activity. ${ }^{6}$ Secondly, the hepatic PAI-1 may represent inhibitor being cleared from the plasma, either as the free molecule or as a complex with t-PA. Thirdly, hepatic PAI-1 may represent a mechanism by which the liver traps and clears t-PA from the circulating plasma. ${ }^{19}$

Spleen contained a high concentration of PAI-1 of relatively low specific activity. Our immunohistochemical studies indicate that it is predominantly present in splenic macrophages. Perhaps such cells synthesise PAI-1, but an alternative possibility is that splenic PAI-1 represents the low activity form of the inhibitor sequestered in the spleen from effete platelets, which themselves contain PAI-1 of relatively low specific activity. ${ }^{6}$ 


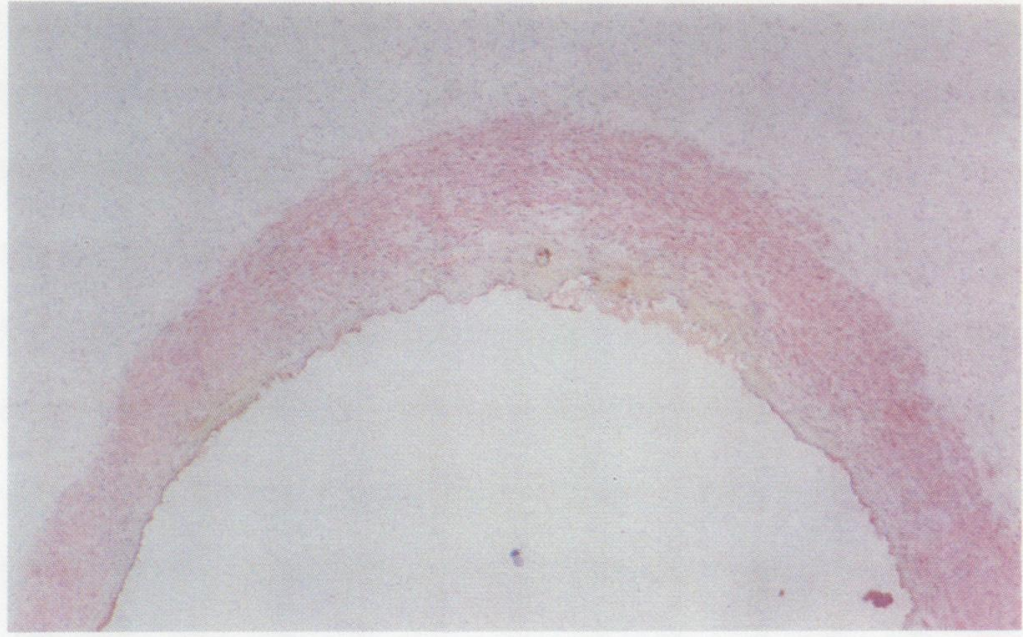

(E) umbilical vein wall, low power, showing positive staining of muscularis layer.

The immunohistochemical studies reported here extend the findings on extracted tissues. In the blood itself they confirm the well known presence of PAI-1 in platelets. ${ }^{45}$ Further high concentrations of PAI-1 were detected in megakaryocytes, thus establishing that platelet PAI-1 represents material derived from their progenitor cells rather than material acquired

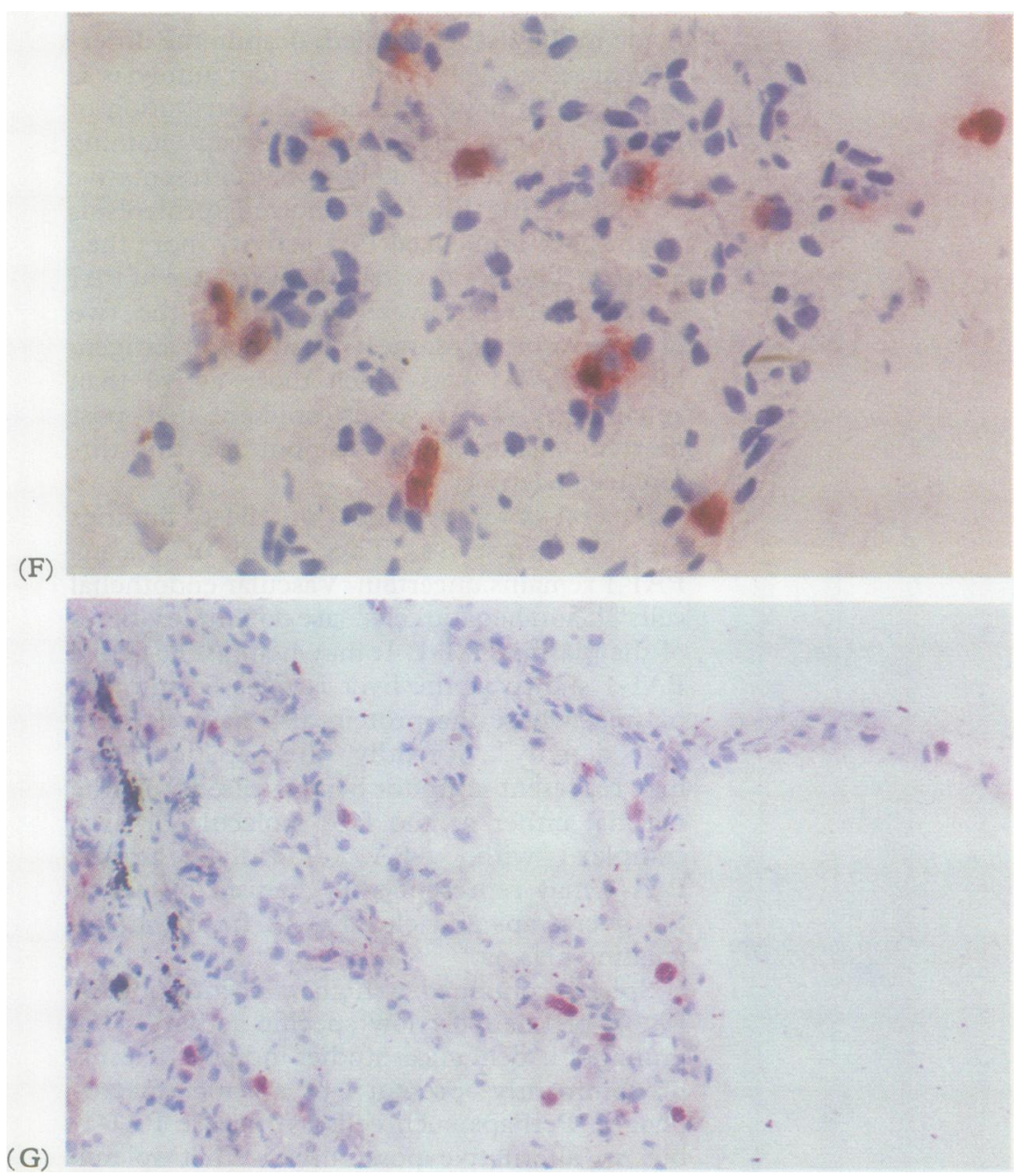

(F) glomerulus, showing selective positive staining; $(G)$ lung, showing positive staining in macrophage population.

Control slides were prepared for each tissue but only one (D) is shown; all were negative. by any other process. Consistent with this, we have shown that a megakaryoblastic cell line, MEG-01, produces PAI-1. ${ }^{20}$

A novel observation was the demonstration of PAI-1 in neutrophil polymorphonuclear leucocytes in peripheral blood. Neutrophils have a central role in the early inflammatory response; they produce a number of active proteases including plasminogen activators. It may be that neutrophil PAI-1 assists in the regulation of local proteolysis in inflammatory processes, perhaps by exerting control of protein breakdown in inflammatory exudates.

In many tissues cells containing PAI-1 were of monocytoid lineage, the antigen being detected in splenic and alveolar macrophages, Kupffer and microglial cells. Macrophages also contain a number of proteases including PA, and if PAI-1 is present in these cells in any of these sites it would be appropriately placed to influence extravascular proteolysis when such cells are active. Lymphocytes themselves did not contain PAI-1.

Predictably, PAI-1 was detected immunohistologically in blood vessel endothelium of human veins and arteries in accordance with studies on cultured endothelial cells in vitro ${ }^{16}{ }^{17}$; in this location it has considerable potential for influencing intravascular fibrinolysis and thus thrombotic or haemorrhagic events. Additionally, however, PAI-1 was detected in large quantities in vascular smooth muscle. This extends to human tissues the observation that PAI activity was detectable in cultured calf smooth muscle cells by Laug, ${ }^{21}$ who suggested that the smooth muscle proliferation seen in atherosclerosis may result in increased PAI concentrations leading to persistence of fibrin in atheromatous plaques. Smooth muscle cells in other sites also contained antigen when studied immunohistochemically and seemed to constitute an important reservoir of PAI-1.

Our observation of large quantities of PAI-1 antigen in a proportion of glomerular cells is probably due to its presence in mesangial cells. These cells share characteristics with smooth muscle cells elsewhere in the body. ${ }^{22}$ We and others ${ }^{23}$ have observed the capacity of such cells to produce considerable quantities of PAI- 1 in culture. Mesangial cell proliferation is a function of some nephropathies. It may be that this increased local concentration of PAI-1, resulting from mesangial proliferation, promotes persistence of fibrin deposited in glomeruli, thus increasing or perpetuating renal dysfunction.

Clearly, PAI-1 is present in plasma, platelets, and vascular endothelium, the elements central to haemostasis. Our observations suggest this PAI-1 may also have a role in regulating extravascular proteolysis in inflammatory and other processes, as indicated by its presence in neutrophil polymorphs, macrophages, and smooth muscle cells. The presence of PAI- 1 , in quantity, in active form in liver suggests that hepatic PAI-1 may represent a source of plasma PAI-1, or that it participates in hepatic clearance of plasma t-PA. The role of PAI-1 in the extravascular compartment merits further study. 
We greatly appreciate the discussion and advice from $\mathrm{Dr} \mathrm{H} \mathrm{F}$ Sewell and Mr G King (immunopathology). We thank Dr I R MacGregor for useful discussion on the antibodies used. We thank $\operatorname{Dr} A$ A Dawson for bone marrow aspirates and members of the Department of Pathology for providing samples at necropsy

The study was funded by the Scottish Home and Health Department, the Scottish Hospital Endowments Research Trust, and the British Heart Foundation.

1 Kruithof EKO. Plasminogen activator inhibitor type 1 biochemical, biological and clinical aspects. Fibrinolysis 1988;2(suppl 2):59-70.

2 Chmielewska J, Ranby $M$, Wiman B. Evidence for a rapid inhibitor to tissue plasminogen activator in plasma. Thromb Res 1983;31:427-36.

3 Kruithof EKO, Tran-Thang C, Ransijn A, Bachmann F. Demonstration of a fast-acting inhibitor of plasminogen activators in human plasma. Blood 1984;64:907-13.

4 Erickson LA, Ginsberg MH, Loskutoff DJ. Detection and partial characterisation of an inhibitor of plasminogen activator in human platelets. J Clin Invest 1984:74: 1465-72.

5 Booth NA, Anderson JA, Bennett B. Platelet release protein which inhibits plasminogen activators. J Clin Pathol 1985;38:825-30.

6 Booth NA, Simpson AJ, Croll A, Bennett B, MacGregor IR Plasminogen activator inhibitor (PAI-1) in plasma and platelets. Br J Haematol 1988;70:327-33.

7 Juhan-Vague I, Moerman B, de Cock F, Aillaud MF, Collen D. Plasma levels of a specific inhibitor of tissue-type plasminogen activator (and urokinase) in normal and pathological conditions. Thromb Res 1984;33:523-30.

8 Juhan-Vague I, Aillaud MF, de Cock F, et al. The fastacting inhibitor of tissue-type plasminogen activator is an acute phase reactant protein. In: Davidson JF, Donati MB, Coccheri S, eds. Progress in fibrinolysis. Vol VII. Edinburgh: Churchill Livingstone, 1985:146-9.

$9 \mathrm{Kluft}, \mathrm{C}$, Verheijen JH, Jie AFH, et al. The postoperative fibrinolytic shutdown: a rapidly reverting acute phase pattern for the fast-acting inhibitor of tissue-type plasminogen activator after trauma. Scand J Clin Lab Invest 1985;45:605-10.

10 Simpson AJ, Booth NA, Moore NR, Bennett B. The platelet and plasma pools of plasminogen activator inhibito
(PAI-1) vary independently in disease. $\mathrm{Br} J$ Haematol 1990;75:543-8.

11 MacGregor IR, Booth NA. An enzyme linked immunosorbent assay (ELISA) used to study the cellular secretion of endothelial plasminogen activator inhibitor (PAI-1) Thromb Haemostas 1988;59:68-72.

12 Chmielewska J, Wiman B. Determination of tissue plasminogen activator and its "fast" inhibitor in plasma. Clin Chem 1986;32:482-5.

13 Laurell C-B. Quantitative estimation of proteins by electrophoresis in agarose gel containing antibodies. Analyt Biochem 1966;15:45-52.

14 Cordell JL, Falini B, Erber WN, et al. Immunoenzymatic labelling of monoclonal antibodies using immune complexes of alkaline phosphatase and monoclonal antialkaline phosphatase (APAAP complexes). $J$ Histochem Cytochem 1984;32:219-29.

15 MacGregor IR, Tonner AM, Micklem LR, James K, Booth NA. Murine monoclonal antibodies against active site epitopes on human endothelial plasminogen activator nhibitor (PAI-1). Fibrinolysis 1990;4:27-34.

16 Loskutoff DJ, Van Mourik JA, Erickson LA, Lawrence D Detection of an unusually stable fibrinolytic inhibito produced by bovine endothelial cells. Proc Natl Acad Sci USA 1983;80:2956-60.

17 Philips M, Juul AG, Thorsen S. Human endothelial cells produce a plasminogen activator inhibitor and a tissueype plasminogen activator-inhibitor complex. Biochem Biophys Acta 1984;802:99-110.

18 Konkle BA, Schuster S, Kelly M, Hassett D. Plasminogen activator inhibitor-1 (PAI-1) mRNA expression in freshly isolated rat liver cells. Fibrinolysis 1990;4(suppl 3): 12 .

19 Wing LR, Hawksworth GM, Bennett B, Booth NA. Clearance of $t-P A, P A I-1$ and $t-P A-P A I-1$ complex in an isolated perfused rat liver system. J Lab Clin Med 1991; (in press).

20 Booth NA, Reith A, Moore NR, et al. Plasminogen activato inhibitors PAI-1 and PAI-2 produced by a megakaryoblastic cell-line MEG-01. Thromb Haemostas 1989; 62:163

21 Laug WE. Vascular smooth muscle cells inhibit plasminogen activators secreted by endothelial cells. Thromb Haemostas 1985;53:165-9.

22 Scheinman JI, Fish AJ, Brown DM, Michael AJ Human glomerular smooth muscle (mesangial) cells in culture. glomerular smooth muscle

23 Lacave R, Rondeau E, Ochi S, Delarve F, Schleuning WD Sraet JD. Characterisation of a plasminogen activator and its inhibitor in human mesangial cells. Kidney Int 1989;35 806-11. 